\title{
Maternal Mortality in 19th- and Early 20th-century Italy
}

\author{
Matteo Manfredini*,**, Marco Breschi ${ }^{\dagger}$, Alessio Fornasin ${ }^{\ddagger}$, \\ Stanislao Mazzoni ${ }^{\S}$, Sergio De lasio** and Alfredo Coppa ${ }^{*}$
}

\begin{abstract}
Summary. Although dramatically reduced in Western and developed countries, maternal mortality is still today one of the most relevant social and health scourges in developing countries. This is the reason why high levels of maternal mortality are always interpreted as a sign of low living standards, ignorance, poverty and woman discrimination. Maternal mortality represents, therefore, a very peculiar characteristic of demographic systems of ancien regime. Despite this important role in demographic systems, no systematic study has been addressed to investigate the impact of maternal mortality in historical Italy. The aim of this article is to shed some light on such a phenomenon by investigating its trend over time and the determinants in some Italian populations between the 18th and the early 20th centuries. The analysis will make use of civil and parish registers linked together by means of nominative techniques, and it will be, therefore, carried out at the micro level.
\end{abstract}

Keywords: maternal mortality; pretransitional; Italy; individual data

Low living standards, illiteracy, poverty, discrimination against women and high maternal mortality are all well-represented in the demographic systems of pretransitional populations in Europe. ${ }^{1}$ These are systems that were characterised, demographically speaking, by high levels of fertility and mortality, respectively, due to the absence of birth control and frequent epidemics. In these populations, pregnancy proved a risky event: there were recurrent waves of puerperal sepsis; infections contracted during childbirth; unskilled midwives; repeated deliveries and general hard work even immediately before and after birth. However, maternal mortality varied across 19th-century European countries

\footnotetext{
*University of Parma, Parco Area delle Scienze, 43100 Parma, Italy. E-mail: matteo.manfredini@unipr.it

** Department of Chemistry, Life Sciences and Sustainability, University of Parma, Parco Area delle Scienze, 43100 Parma, Italy

${ }^{\dagger}$ Department of Economics and Business, University of Sassari, via Muroni 25, 07100 Sassari, Italy

‡Department of Economics and Statistics, University of Udine, via Tomadini 33/A, 33100 Udine, Italy

§Institute of Economy, Geography and Demography, Spanish National Research Council, Center for Humanities and Social Sciences, C/ Albasanz, 26-28, 28037 Madrid, Spain

\#Department of Environmental Biology, University La Sapienza, P.le Moro 5, 00185 Rome, Italy.

Matteo Manfredini is an Associate Professor of Demography at the University of Parma. He is a member of the scientific committee of the Italian Society of Historical Demography and of the Asociación de Demografía Histórica Iberica. His research activity is mainly devoted to the study of demographic mechanisms and processes in past populations, often investigated at the individual level. He is author/co-author of many publications on the most important journals of demography and historical demography and on some important volumes.
}

${ }^{1}$ E. A. Hammel and A. Gullickson, 'Maternal Mortality as an Indicator of the Standard of Living in Eighteenth and Nineteenth Century Slavonia', in R. C. Allen, T. Bengtsson and M. Dribe, eds, Living Standards in the
Past: New Perspectives on Well-Being in Asia and Europe (Oxford: Oxford University Press, 2005), 277306.

(c) The Author(s) 2019. Published by Oxford University Press on behalf of the Society for the Social History of Medicine. doi:10.1093/shm/hkz001 
as a result of differences in the onset of the demographic transition; in the level of trained medical assistance during delivery and in the diffusion of effective treatments.

During that period, Italy had a peculiar position in the European context. Not only was it politically fragmented, and one of the less developed areas, at least up to 1861, but it was also one that comprised of populations with the slowest process of demographic transition, something that makes Italy quite different from the other European countries for which maternal mortality indicators have been calculated. Given this, one would expect levels of maternal mortality in Italy to be amongst the highest in Europe. However, only a few local studies on small Italian communities have been carried out, ${ }^{2}$ which limits not only the possibility of situating Italian maternal mortality in the larger European context but also robs us of a comprehensive sense of female health conditions in pre-industrial Italy. This article aims, first of all, to fill that gap by providing a first systematic analysis of maternal mortality in 19th- and early 20th-century Italy. This will be done not only by analysing national statistics from 1862 onwards but also by investigating a sample of Italian communities from North to South using reconstructed individual data. This approach not only enables us to outline a picture of the levels of maternal mortality across 19th- and early 20th-century Italy. It also allows a more in-depth analysis of the determinants of maternal mortality in the country.

The article is divided into five sections. The section 'The Aetiological Mechanisms of Maternal Mortality in Pretransitional Populations' describes possible aetiological mechanisms of maternal mortality in 19th- and early 20th-century Europe. The section 'Maternal Mortality in Europe: A Brief Outline' illustrates the patterns of maternal mortality in some selected European countries based on some of the socio-economic, demographic and health factors associated with maternal mortality. Using the same indicators, the section 'The Italian Context' discusses the position of Italy within the European context in the 19th and early 20th centuries. The section 'The Italian Population Sample: Description and Analysis' provides an outline of the local populations studied, the potentialities and limitations of the sources used, and, finally, a discussion of maternal mortality from such a sample of Italian local populations.

\section{The Aetiological Mechanisms of Maternal Mortality in Pretransitional Populations}

From a theoretical point of view, the risk factors for maternal mortality can be divided into two main groups, direct and indirect factors. ${ }^{3}$ Direct causes of maternal morbidity and mortality result from complications in pregnancy and childbirth. They include haemorrhage, infection, high blood pressure, unsafe abortion and obstructed labour. The most common cause of death in the 19th century was puerperal sepsis, a general and systemic infection during or after childbirth, the aetiologic agents of which were usually streptococci or staphylococci. These developed on the uterus and the placenta, and the infection either remained there or spread beyond it, passing into the bloodstream

${ }^{2}$ A. M. Gatti, 'Nascita dell'ostetricia e mortalità materna in Sardegna', Bollettino di Demografia Storica, 1999, 30/31, 79-94; G. Silini, 'Metodologia e risultati preliminari di uno studio sulle cause di morte a Lovere nel secolo XIX', in Popolazione, Società e ambiente. Temi di demografia storica italiana (secc. XVII-XIX), (Bologna: Clueb, 1990), 331-52.
${ }^{3} U$. Högberg, 'Maternal Mortality in Sweden' (Medical dissertation New Series, No 156, Umeå University, 1985); World Health Organization, The WHO Application of ICD-10 to Deaths During Pregnancy, Childbirth and the Puerperium: ICD-MM (Geneva: WHO, 2012). 
causing peritonitis and septicaemia with high fever, anorexia and low blood pressure. As demonstrated in those developing countries in which data on causes of death are available, direct causes of maternal death, in particular sepsis, are usually associated with how young someone is at childbirth and low parity, especially primiparity. ${ }^{4}$

Indirect causes of maternal mortality include all the deaths due to pre-existing conditions aggravated by pregnancy or diseases developed during pregnancy, but not directly connected to obstetric complications, such as pneumonia, malaria and other illnesses. In pre-industrial societies, according to Perrenoud and Imhof, the part of maternal mortality not directly connected with childbirth was also associated with a 'progressive deterioration of a mother's health in the course of her reproductive life' ${ }^{5}$ What we term now as maternal depletion syndrome ${ }^{6}$ is a process in which repeated reproductive cycles, the need to work during and immediately after pregnancy and poor nutrition could lead mothers to physical and psychological exhaustion. ${ }^{7}$ These factors could break the delicate equilibrium between nutrient intake and energy expenditure, leading to weight loss and nutrient drainage. This could, in turn, make women more susceptible to anaemia, infections and fatigue, thereby reducing their chances of survival. Maternal depletion is, as such, a syndrome produced by the interaction of many social and physiological factors, whose disentanglement results, however, quite difficult in a historical context. Poor nutrition is now regarded as the key element of this condition, ${ }^{8}$ but there are also biodemographic factors that can be associated with maternal depletion syndrome. These include high parity, short birth intervals and late age at childbirth. ${ }^{9}$ The combination of these

${ }^{4}$ B. Bako et al., 'Risk Factors and Microbial Isolates of Puerperal Sepsis at the University of Maiduguri Teaching Hospital, Maiduguri, North-Eastern Nigeria', Archives of Gynecology and Obstetrics, 2012, 285, 913-17; S. S. Shamshara and B. Rauf, 'Puerperal Sepsis-Still a Major Threat for Parturients', Journal of Ayub Medical College Abbottabad, 2010, 22, 18-22; C. Abouzahr, E. Aaahman and R. Guidotti, 'Puerperal Sepsis and Other Puerperal Infections', in C. J. L. Murray and A. D. Lopez, eds, Health Dimensions of Sex and Reproduction: The Global Burden of Sexually Transmitted Diseases, Maternal Conditions, Perinatal Disorders, and Congenital Anomalies (Geneva: World Health Organization); A. C. Seale et al., 'Maternal and Early Onset Neonatal Bacterial Sepsis: Burden and Strategies for Prevention in Subsaharan Africa', The Lancet Infectious Diseases, 2009, 9, 428-38.

${ }^{5} \mathrm{~A}$. Perrenoud, 'Surmortalité féminine et condition de la femme (XVIle-XIXe siècles). Une vérification empirique', Annales de Démo graphie Historique, 1981, 89104; A. E. Imhof, 'The Amazing Simultaneousness of the Big Differences and the Boom in the 19th century. Some Facts and Hypotheses about Infant and Maternal Mortality in Germany, 18th to 20th Century', in T. Bengtsson, G. Fridlizius and R. Ohlsson, eds, Pre-Industrial Population Change. The Mortality Decline and Short-Term Population Movements (Stockholm: Almquist and Wiksell, 1984), 191-222; M. Oris, M. Neven and G. Alter, 'Maternal Depletion and the Survival Chances of Infants and Children in
Nineteenth-Century Eastern Belgium', in M. Breschi and L. Pozzi, eds, The Determinants of Infant and Child Mortality in Past European Populations (Udine: Forum, 2004), 153-74.

${ }^{6}$ D. B. Jelliffe and I. Maddocks, 'Notes on Ecologic Malnutrition in the New Guinea Highlands', Clinica Pediatrica, 1964, 3, 432-38.

${ }^{7} \mathrm{P}$. A. Higgins and H. Alderman, 'Labor and Woman's Nutrition. The Role of Work Effort and Fertility on Nutritional Status in Ghana', Journal of Human Resources, 1997, 32, 577-95; K. M. Merchant, R. Martorell and J. D. Haas, 'Maternal and Fetal Responses to the Stress of Lactation Concurrent with Pregnancy and Recuperative Intervals', The American Journal of Clinical Nutrition, 1990, 52, 280-88.

${ }^{8}$ A. Winkvist, K. M. Rasmussen and J. P. Habicht, 'A New Definition of Maternal Depletion Syndrome', American Journal of Public Health, 1992, 82, 691-94. ${ }^{9}$ A. Conde-Agudelo and J. M. Belizan, 'Maternal Morbidity and Mortality Associated with Interpregnancy Interval: Cross Sectional Study', British Medical Journal, 2000, 321, 1255-59; N. Kozuki et al., 'The Associations of Birth Intervals with Smallfor-Gestational-Age, Preterm, and Neonatal and Infant Mortality: A Meta-Analysis, BMC Public Health, 2013, 13; J. C. King, 'The Risk of Maternal Nutritional Depletion and Poor Outcomes Increases in early or closely spaced pregnancies', The Journal of Nutrition, 2003, 133, 1732-36. 
factors could make woman's physical exhaustion more likely, but they could not alone cause the syndrome.

The effects of all the elements described earlier are then expected to be associated with and mediated by poverty, the low social position of women, ignorance and lack of health facilities and skilled assistance during and after delivery. A correct approach should, therefore, include proxies of the socio-economic background of mothers as context variables in the analysis of the determinants of maternal mortality.

The evidence that maternal mortality has varied a great deal in past times is just the consequence of the different combination of the above-mentioned factors in various contexts. There is, of course, also, the role that the quality of sources, the accuracy and detail of available data and of the criteria adopted to define maternal mortality might play in our perceptions of these realities.

\section{Maternal Mortality in Europe: A Brief Outline}

As will be evident from the theoretical framework described earlier, maternal mortality is expected to be lower in the most developed countries and in those ahead in the process of demographic transition. The two features are obviously interrelated, affecting the drop of maternal mortality in two different ways. First, mothers living in more developed countries experience intrinsically lower mortality due to medical progress and the diffusion of state medical support, better hygiene and improvements in nutrition; secondly, fewer children per woman, as is typical of transitional countries, reduced the risk of maternal death.

Sweden and England are useful examples here. In these countries, maternal mortality in mid-18th century was around 12-13 per thousand, just when crude mortality rates had begun to decline, more slowly in England (-12 per cent between 1750 and 1850), and more quickly in Sweden (25 per cent in the same period). As for fertility, in both countries, it started to decline sharply and continuously, after some fluctuations, only in the late 19th century. ${ }^{10}$ In parallel with overall mortality, maternal mortality dropped by 30-40 per cent in the second half of the 18th century and continued to decline in the 19th century: it fell eventually to around 5 mothers' deaths per thousand births. ${ }^{11}$ France was the European country where the process of demographic transition started earliest. Mortality rates, in fact, declined there by a remarkable 34 per cent between 1750 and 1850, while fertility had dropped steeply since the mid-18th century. ${ }^{12}$ Thus, in the second half of the 18th century, maternal mortality had already begun its

${ }^{10}$ For a reconstruction of mortality rates series for European countries, see A. Perrenoud, 'The Attenuation of Mortality Crises and the Decline of Mortality', in R. Schofield, D. Reher and A. Bideau, eds, The Decline of Mortality in Europe (Oxford: Clarendon Press, 1991), 18-37; for fertility rates, see J. Vallin, 'Europe's Demographic Transition', in G. Caselli, J. Vallin and G. Wunsch, eds, Demography: Analysis and Synthesis, Vol. III (Amsterdam: Elsevier, 2006), 41-66.

${ }^{11}$ For the decline in maternal mortality in Sweden and England, see Högberg, 'Maternal Mortality' and V. De Browere, 'The Comparative Study of Maternal
Mortality Over Time: The Role of The Professionalisation of Childbirth', Social History of Medicine, 2007, 20, 541-62; R. Schofield, 'Did the Mothers Really Die? Three Centuries of Maternal Mortality in "The World We Have Lost"', in L. Bonfield, R. M. Smith and K. Wrightson, eds, The World We Have Gained. Histories of Population and Social Structure (Oxford: Basil Blackwell, 1986), $231-$ 60; E. Wrigley et al., English Population History from Family Reconstitution 1580-1837 (Cambridge: Cambridge University Press, 1997).

${ }^{12}$ Perrenoud, 'The Attenuation of Mortality Crises', 30; Vallin, 'Europe's Demographic Transition', 50. 
decline. ${ }^{13}$ However, the decline was slower than that in Sweden and England, with values estimated by Wrigley and colleagues only a little under 10 per thousand in the 19th century. ${ }^{14}$ In other European countries, the situation was much more similar to France than to Sweden and England. In the mid-19th century, Germany had high levels of maternal mortality, close to 12 per thousand, while Slavonia (a region in present-day Croatia) showed an increasing trend until after the 1860s, with peaks over 16 per thousand. Interestingly, such a rise in maternal mortality was attributed to the withdrawal of male labour from peasant families due to military mobilisation, which made households (and their members) more fragile and vulnerable. ${ }^{15}$

Along with progress in medicine and the introduction of vaccines, ${ }^{16}$ various authors attribute a key role in the decline in maternal mortality to the introduction of home-based midwifery assistance and, especially during the 19th century and the spread of industrialisation, to public health policies such as the legal protection of women and working mothers. ${ }^{17}$ Professional regulations of trained midwives were, in fact, introduced in Sweden in the late 17th century, a period in which midwifery schools started to be active in England, although the formal regulation of professional midwifery began only in 1902. ${ }^{18}$ Trained midwives had been active since the 18th century in France, where, however, a law protecting motherhood was enacted only in 1874 (the Roussel bill); stricter legislation limiting the number of hours worked by women came only in the very early 1900s. ${ }^{19}$ This occurred later than in other European countries, such as Britain, where governments had concerned themselves with the protection of children and women working in the mines and mills since 1802 and the first Mines and Factory Acts. ${ }^{20}$

Beyond national maternal mortality figures, local variability proved the norm, with marked differences especially between cities and the countryside. For example, mid19th-century London had higher maternal mortality levels compared to England as a whole, while in 19th-century Belgium, maternal mortality could vary from a modest 5 per thousand in Limburg to 11.8 in Sart, a pattern similar to that found in the same period in France, where scholars have documented figures from 10 per thousand in the city of Rouen to 17 per thousand in the village of Mogneneins, to higher rates (around 50 per thousand) in the maternal hospitals of Marseille and Port Royal. ${ }^{21}$

\footnotetext{
${ }^{13} \mathrm{H}$. Gutierrez and J. Houdaille, 'La mortalité maternelle en France au XVIII ${ }^{\mathrm{e}}$ siecle', Population, 1983, 38, 975-97.

${ }^{14}$ Wrigley et al., English Population History, 315.

${ }^{15} \mathrm{Hammel}$ and Gullickson, 'Maternal Mortality as an Indicator of the Standard of Living', 333.

${ }^{16} \mathrm{See}$, for instance, the vaccination campaigns against smallpox in England and Sweden: A. J. Stewart and P. M. Davlin, 'The History of the Smallpox Vaccine', Journal of Infection, 2006, 52, 329-34; P. Skold, 'From Inoculation to Vaccination: Smallpox in Sweden in the Eighteenth and Nineteenth Centuries', Population Studies, 1996, 50, 247-62.

${ }^{17} \mathrm{U}$. Högberg, 'The Decline in Maternal Mortality in Sweden. The Role of Community Midwifery', American Journal of Public Health, 2004, 98, 131220; Mothers De Browere, 'The Comparative Study of Maternal Mortality Over Time', 541.
}

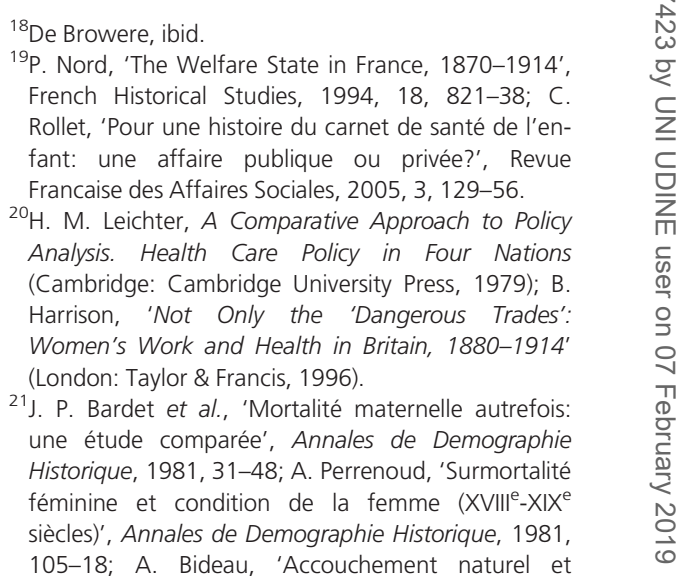


It is obvious, however, that any comparison at the national or local level may suffer from inconsistencies in data quality, in the definition of maternal mortality adopted and in the calculation of maternal mortality rates.

\section{The Italian Context}

In the earlier section, we described the maternal mortality pattern in some European countries and how that pattern is associated with elements of the socio-demographic background of those nations between the 18th and the 19th centuries. Before looking in more detail at the levels and determinants of maternal mortality in Italy based on our population samples, it is, therefore, fundamental, using the same indicators, to provide some background to the demographic, socio-economic and political elements of the country. This will help us not only in assessing its position within Europe but also in contextualising the results on maternal mortality shown further. ${ }^{22}$ From a demographic point of view, Italy experienced a late demographic transition. In the period 1750-1850, it did not show, unlike the countries described earlier, any substantial decline in mortality, with the overall mortality rate fluctuating around 31-32 deaths per thousand people per year and with very high levels of infant mortality at the beginning of the 20th century (166 infant deaths per thousand births in 1901). ${ }^{23}$ Mortality, in fact, started to decline only after 1880 , followed 10 years later by a widespread drop in fertility. ${ }^{24}$

As for the socio-economic situation, Italy was a latecomer to the industrial revolution. This backwardness is reflected in the share of male subjects working in the agricultural sector: over 70 per cent in 1861 (and still over 60 per cent in 1901), substantially more than most other Western European countries, such as England (19.3 per cent in 1871). ${ }^{25}$ In this poor economic context, women had low labour force participation rates, around 50 per cent in 1881, dropping to a little over 40 per cent in $1901 .{ }^{26}$ Illiteracy is probably the best indicator of Italy's slow development with respect to the most industrialised European countries of the period. Illiteracy in Italy stood, in fact, at 67.2 per cent in 1881, and was still common, especially among female subjects, around 1900, when it stood at 56.0 per cent, against figures below 5 per cent for Sweden, England and France. ${ }^{27}$

accouchement à haut risque. Chatellerie de Thoissyen-Dombes, 1660-1814', Annales de Demographie Historique, 1981, 49-66; G. Boetsch, E. Rabino Massa and S. Bello, 'Accouchements and mortalité maternelle a l'Hotel-Dieu de Marseille au milieu du XIX siecle', Bulletin e Mémoires de la Société d'Anthropologie de Paris, 1998, 10, 425-41; S. Beauvalet, 'Perdre la vie en la donnant : la mortalité maternelle à Port-Royal, 1815-1826', Annales de Demographie Historique, 1994, 237-60.

${ }^{22}$ It is worth remembering that Italy became a political state only in 1861 and that until that year it was broken up into many little states. National figures up to 1861 represent, therefore, only a partial picture of the deep regional variability in Italy in those years.

${ }^{23}$ Actually, the mortality figures for the period 17501850 refer to North Italy. See P. R. Galloway, 'A Reconstruction of the Population of North Italy from 1650 to 1881 Using Annual Inverse Projection with
Comparisons to England, France, and Sweden', European Journal of Population, 1994, 10, 223-74.

${ }^{24} \mathrm{M}$. Livi Bacci, A History of Italian Fertility During the Last Two Centuries (Princeton: Princeton University Press, 2015).

${ }^{25}$ R. C. Allen, 'Economic Structure and Agricultural Productivity in Europe, 1300-1800', European Review of Economic History, 2000, 3, 1-25; L. ShawTaylor and E. Wrigley, 'Occupational Structure and Population Change', in R. Floud, J. Humphries and P. Johnson, eds, The Cambridge Economic History of Modern Britain (Cambridge: Cambridge University Press, 2014), 53-88.

${ }^{26} \mathrm{G}$. Mancini, 'Women's Labor Force Participation in Italy, 1861-2016', HHB Working Paper Series, No. 8, December 2017, Rome.

${ }^{27}$ R. H. Steckel and R. Floud, 'Conclusions', in R. H. Steckel and R. Floud, eds, Health and Welfare During Industrialization (Chicago: University of Chicago Press, 1997), 423-50. 
Women's lower participation in the labour force and lower literacy rates give the idea of women's inferior social position in Italian society in the 19th and early 20th centuries, a condition that was also reinforced by a cultural model strongly permeated by Catholic and family values, which assigned women primarily the role of housewives and mothers. ${ }^{28}$ Catholic 'familism' went hand in hand with the existence of limited state support for women and mothers, which made the household the only institution able to provide some form of protection. With the absence of the state, home birth was the norm. This was not only because the few maternity hospitals tended to be devoted to the care of unmarried mothers and their offspring but also because distrust of science and medical doctors discouraged pregnant women from having births in institutions. Indeed, private and public maternity hospitals, who had provided assistance and care for infants and newly mothers since the end of the 18th century, catered, especially in cities, only to a minority of mothers. Women usually gave birth at home with the assistance of non-professional midwives, despite the fact that many midwifery schools had been open in Italy since the 17th century. This was especially true in the countryside, where rural families did not welcome outside midwives even if they were better trained. This suspicion of modern birthing methods was so deep-rooted in Italian society that in 1953, home births still accounted for 80 per cent of all births. ${ }^{29}$

What emerges from the few descriptive notes provided earlier is that the health of Italian women was not sufficiently guaranteed when they gave birth, especially when compared with the most developed European countries. Lack of hospital facilities for new mothers, limited use of trained midwives, general ignorance and poor socioeconomic conditions were, in fact, common in Italy in the 19th and early 20th centuries.

\section{The Italian Population Sample: Description and Analysis}

As described earlier, 19th-century Italy was characterised by the absence of laws on maternal protection for the whole peninsula before 1861, by strong asymmetries in demographic and family systems across the territory with regional differences in socioeconomic conditions and by an unequal distribution of hospital facilities for mothers and parturients. As a result, researchers interested in the history of maternal mortality in Italy need to collect data from local populations situated in different parts of the country. And this is exactly what we have done by selecting seven Italian populations between the 19th and 20th centuries. Such populations differ in many respects, representing different regions and socio-economic contexts. Madregolo and the parishes of the Upper Parma Valley (Corniglio, Palanzano and Monchio delle Corti) are located in northern Italy, in what once was the Duchy of Parma and Piacenza. Madregolo is located on the plain close to the Taro river, while the three parishes of the upper Parma valley are on the mountains, 50-60 km south of Parma. Casalguidi and Civitella del Tronto are in central Italy in the Grand Duchy of Tuscany and in the Bourbon Kingdom of Naples, respectively.

${ }^{28}$ D. I. Kertzer and R. P. Saller, eds, The Family in Italy: From Antiquity to the Present (New Haven: Yale University Press, 1991); E. Ruspini, 'Role and Perceptions of Women in Contemporary Italy', in A. Mammone, E. Giap Parini and G. A. Veltri, eds, The Routledge Handbook of Contemporary Italy. History,
Politics, Society (London and New York: Routledge, 2015), 64-76.

${ }^{29}$ For the sake of comparison, in mid-20th-century England, the share of home births was quite lower, around 35 per cent. A. Nove, A. M. Berrington and Z. L. Matthews, 'Home Births in the UK, 1955 to 2006', Population Trends, 2008, 133, 20-27. 
Table 1. Some features of the populations studied

\begin{tabular}{lllrrr}
\hline Community & \multicolumn{1}{c}{ Source } & \multicolumn{1}{c}{ Period } & Mean pop. size & IMR & TMFR \\
\hline Madregolo & Parish registers+S.A. & $1761-1883$ & 550 & 220 & 10.1 \\
Val Parma & Parish registers & $1761-1883$ & 10,100 & 155 & 10.4 \\
Casalguidi & Parish registers+S.A. & $1819-1859$ & 2,400 & 200 & 11.6 \\
Civitella & Civil registers & $1809-1940$ & 8,500 & 160 & - \\
Alghero & Civil registers & $1866-1935$ & 11,100 & 176 & 7.4 \\
\hline
\end{tabular}

Note: Infant mortality rate (IMR) is the number of deaths in the first year of life per thousand births; Total marital fertility rate (TMFR) is the number of children per married woman. S.A.; Status Animarum.

Casalguidi is halfway between the cities of Florence and Pistoia, while Civitella is in the present-day Abruzzo region, on the hills $20 \mathrm{~km}$ south of the town of Ascoli Piceno. Finally, Alghero is an important city located in north-western Sardinia, once a possession of the Kingdom of Sardinia. In 1861, the year of the Italian unification, all these communities became part of the Kingdom of Italy.

Table 1 shows some demographic indicators of the selected populations, namely the mean population size, infant mortality rate and total marital fertility rate. Beyond the intrinsic local variability, these indicators depict undoubtedly a pretransitional (or early transitional) context, with high mortality and high fertility levels. On the other hand, from an economic point of view, the populations analysed were largely rural in the periods under consideration, except for Civitella del Tronto and Alghero, whose socio-economic structure was more complex. In particular, Civitella was characterised by a relatively high number of resident soldiers, while in Alghero, sheep farming and sea-related activities were not uncommon. ${ }^{30}$ In addition, Alghero, as a 'city', was also the only population, in our sample, to have a hospital for the assistance of parturients in the period. ${ }^{31}$ In the villages of Madregolo and Casalguidi, sharecropping was the common system of land tenure, although there were also poor day labourers. The presence of sharecroppers was associated with the establishment of large and complex households, which made the social structure in Madregolo and Casalguidi quite different from that of all the other populations studied here. ${ }^{32}$ This agricultural system dominated by landless peasants contrasts with the one existing in Civitella and the upper Parma valley, ${ }^{33}$ where most farmers were smallholders involved in sheep farming activities.

To investigate maternal mortality in the sample populations, we used a data set including all the births in these communities where a mother's life status after childbirth is known. The sources we used to construct this collection of births differ because of the

\footnotetext{
${ }^{30}$ The military community abandoned Civitella progressively after 1861, thereby depriving the community of a key element in the local economic and social system. S. De lasio et al., 'Analisi per cognomi ricavati da differenti serie storiche', in D. A. Obinu and P. Francalacci, eds, Biodemografia e genetica. 400 anni di storia attraverso l'analisi dei cognomi (Nuoro: Studiostampa, 2002), 145-66.

${ }^{31} \mathrm{M}$. Breschi et al., 'Socioeconomic Conditions, Health and Mortality from Birth to Adulthood, Alghero 1866-1925', Explorations in Economic History, 2011, 48, 366-75.
}

${ }^{32}$ M. Breschi, R. Derosas and M. Manfredini, 'Mortality
and Environment in Three Emilian, Tuscan, and
Venetian Communities, 1800-1883', in T.
Bengtsson, C. Campbell and J. Lee, eds, Life under
Pressure: Mortality and Living Standards in Europe
and Asia, 1700-1900 (Cambridge: Massachusetts
Institute of Technology Press, 2004), 209-52.
${ }^{33}$ E. Siri and E. Lucchetti, 'Andamento stagionale dei
matrimoni nell'alta Val Parma (1600-1959)',
Antropologia Contemporanea, 1989, 12,31-49. 
different time intervals investigated. For the Val Parma, Madregolo and Casalguidi, data came from the parish registers of baptism, marriage and burial, whose individual information have been associated by means of family reconstitution methods, based on nominative linkage. This technique has two major goals. First, it allowed us to reconstruct the life history of each person, as well as the offspring of each mother. Secondly, thanks to the linkage procedure we were able to recover some information that was not directly recorded in the religious registers. The mother's age at birth was, in fact, never recorded, while age at death only sometimes. Both had, therefore, to be estimated by linking individual information from different acts. For the parish of Madregolo and Casalguidi, a further religious register has been employed for family reconstitution, namely the 'Status Animarum'. This was a sort of census drawn up by the priest each Easter, in which he recorded each family in the village along with individual information such as name, surname, age, marital status and each household member's relationship to the household head. ${ }^{34}$ The same methodology has been applied to the information available in the civil records of the municipalities of Civitella del Tronto and Alghero. Civil records are concerned with important events in a person's life taken by the local authority: these include birth, marriage and death certificates. ${ }^{35}$ The advantage of civil records is that they report precise dates. Birth certificates, for instance, record the precise date of birth, information not always recorded in the religious registers of birth, which may report, instead, the date of baptism. It is well known that baptism could sometimes take place days after birth. The determination of maternal mortality and the calculation of the distance between a child's birth and mother's death might, then, prove inaccurate for populations whose reconstruction is based on parish registers. ${ }^{36}$

Due to differences in the nature, accuracy and completeness of the sources, the information collected differs across populations. A mother's age is usually available, but in Val Parma, the mother's age at birth is missing for about 20 per cent of the birth records. ${ }^{37}$ Parity is obviously undetermined for all those couples whose marriages were not recorded locally, with particularly high levels in Madregolo (about 48 per cent) due to the high mobility of the population.

A measure of the general level of mortality (crude death rate) is available year after year with the exception of only a few years in Madregolo and Val Parma. Household composition data are obviously present where census-like sources are available, that is, in Madregolo and Casalguidi, while non-demographic information, such as grain prices, varies

\footnotetext{
${ }^{34}$ Parish registers are often the only source to study pre-unitary Italian populations. However, the information was recorded for a religious purpose, so that sometimes they present some gaps and inaccuracies. For instance, birth acts may report the date of baptism instead of the date of birth, death acts never report the cause of death and only rarely the age at death, whilst marriage acts only record the marriages celebrated in the parish. Marriages of parishioners celebrated elsewhere are not mentioned. For more insight into the structure and content of Italian parish registers and on linkage procedures, see $\mathrm{M}$. Manfredini, 'L'utilizzo degli Status Animarum nelle ricostruzioni nominative: miglioramenti informativi
}

qualitativi e quantitativi. II caso di Madregolo (16291914)', Bollettino di Demografia Storica, 1996, 24/ 25, 113-29.

${ }^{35}$ For the population of Alghero, civil records have been integrated with information taken from parish registers (baptisms, burials and marriages).

${ }^{36}$ For example, six mothers in the Val Parma population died some days before the child's birth, which is an obvious result of using baptism dates instead of the date of birth.

${ }^{37}$ We can have information on mother's age at birth via direct records (especially for civil records) or through calculations based on the nominative linkage of parish acts. 
from place to place. Prices data are always available for Casalguidi and always missing for Civitella del Tronto; for Madregolo and Val Parma, they are missing for the 18th century, while for Alghero, no price information is available between 1923 and 1935.

Due to a general absence of information on causes of deaths, each study investigating maternal mortality in pretransitional Italy, ours included, must be based on an indirect definition of maternal mortality, which considers maternal deaths to be those that took place within 60 days of childbirth. Gatti provided a detailed study of the Sardinian parish of Ales, determining a level of maternal mortality of 10.9 deaths per thousand live births in the period $1695-1825 .{ }^{38}$ She found evidence that the central part of the 18th century presented the highest values, between 11 and 16 per thousand, while the mean value for the first 25 years of the 19th century was 9.2 per thousand. Silini conducted a similar study for the population of Lovere (Lombardy) for 1816-65, estimating a lower level of maternal mortality, around 8 deaths per thousand live births. This, although, was calculated for a shorter period after delivery, namely the first 30 days after childbirth. ${ }^{39}$ These values are relatively high according to what was reported in the first section, but they are far from being representative of Italian society.

A more exhaustive and indicative analysis of the levels of maternal mortality in Italy can be carried out using official data on causes of deaths. ${ }^{40}$ In Italy, this information started to be recorded in 1881, although it was limited to the death certificates in chief towns. It is only in 1887 that this practice was extended to the whole of Italy, making it possible to assess the levels of mortality due to the report 'Malattie della gravidanza, parto e puerperio' [illnesses related to the pregnancy, delivery and post-partum period]. Figure 1 shows the evolution of the maternal mortality rates in Italy between 1887 and 1955.

The first clear discontinuity occurred around 1890, when the rate dropped markedly from values of $6.0-5.3$ to 4.1 maternal deaths per thousand live births. This is likely connected with the increasing use of antiseptics in Italian hospitals. ${ }^{41}$ After that decline, the rate remained steady around 2.5-3.0 per thousand until 1937, when it started to drop to levels just above 1 per thousand. This decline in maternal mortality, especially from 1937 onwards, is closely associated with the decline of the per cent of maternal deaths due to septicaemia, due to the introduction of sulfonamides in the treatment of puerperal sepsis. In 1887, about 70 per cent of maternal deaths were due to this blood infection, a proportion that fell lower in 1955, when only 12.8 per cent of maternal deaths were a consequence of septicaemia.

However, the impact of maternal mortality differed in the various Italian regions. Generally speaking, southern Italy had higher values than central and northern regions, ${ }^{42}$ with Sardinia having, at the end of the 19th century, the highest level of maternal mortality (5.3 deaths per thousand births in 1889-92). ${ }^{43}$ Beyond reasons of economic nature,

\footnotetext{
${ }^{38}$ Gatti, 'Nascita dell'ostetricia', 85.

${ }^{39}$ Silini, 'Metodologia e risultati preliminari', 342.

${ }^{40}$ Data extracted and elaborated from Central Institute of Statistics, Annuario di Statistiche Demografiche (Rome: A.BE.T.E., 1955).

${ }^{41}$ A. Angeli and S. Salvini, 'Mortalità per genere e salute riproduttiva: il percorso italiano tra Ottocento e Novecento', Popolazione e Storia, 2001, 1, 71-106.
}

\footnotetext{
${ }^{42}$ Central Institute of Statistics, 'Sviluppo della popolazione italiana dal 1861 al 1961', Annali di Statistica, 1965,17

${ }^{43}$ In Sardinia, the first state-trained midwives appeared only in the 1920s. However, they came mainly from the mainland and were not welcomed by local families.
} 


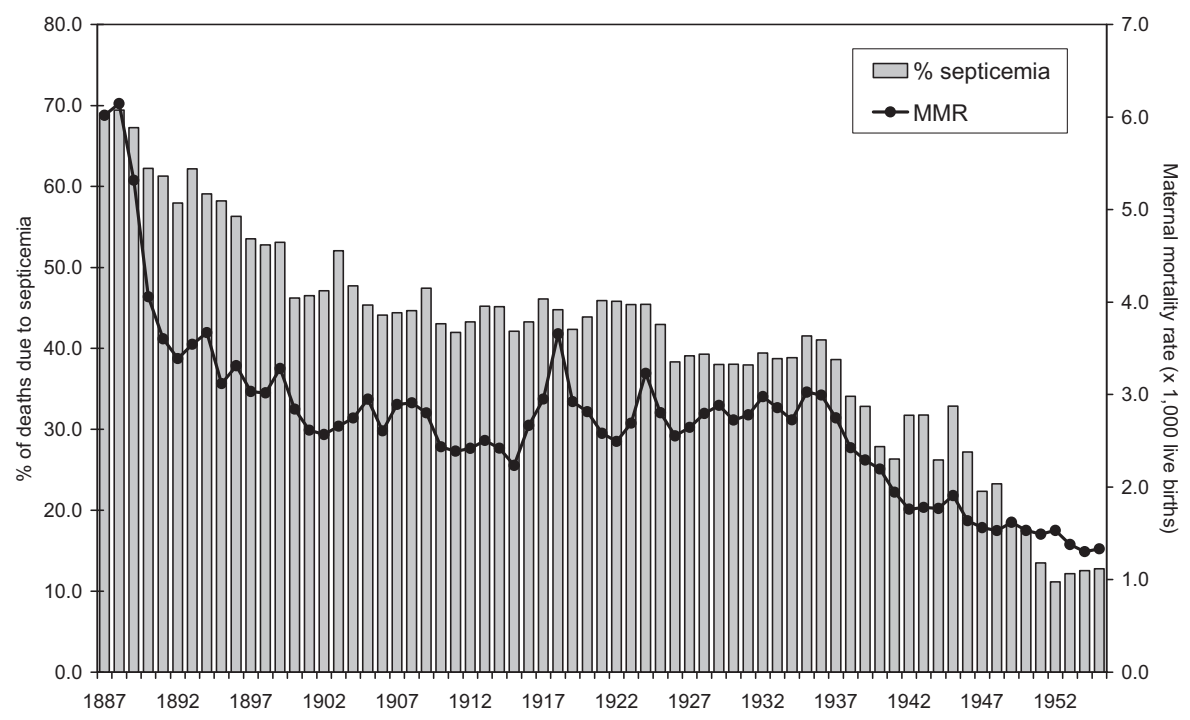

Fig. 1 Maternal mortality rate and per cent of maternal deaths for septicaemia in Italy, 1887-1955.

this situation was also the consequence of a smaller network of hospitals, a lack of skilled assistance to parturients and the stronger influence of the Church in the local approach to maternity and maternal care. ${ }^{44}$

Unfortunately, these statistics cover only Italy after unification, saying nothing about the situation before 1887 . The selection of the population studied in this article offers vice versa the opportunity to study maternal mortality also for the pre-1861 period. The numbers and rates of maternal deaths in the populations studied are displayed in Table 2.

Apart from the data concerning the 18th-century Parma Valley, which are so low as to cast doubt on their accuracy ( 5 deaths per thousand live births) especially in comparison with the figures elsewhere, the lowest levels of maternal mortality in the 19th century were from Civitella del Tronto (4.2 per thousand). Casalguidi and Alghero, on the other hand, show higher values (6.7 and 6.8 per thousand, respectively), but not as high as those estimated for the Parma Valley (8.4 per thousand). The first 35 years of the 20th century saw, in Civitella and Alghero, a marked drop in the maternal mortality rate, which fell to about 4 deaths per thousand live births in both populations. Overall, the data indicate levels of maternal mortality about 6.7 per thousand in the 19th century and 4.0 per thousand in the first 35 years of the 20th century. These figures are consistent with the national levels that are shown in Figure 3. Moreover, the value of the maternal mortality rate for the city of Alghero appears consistent with that found by Gatti, once the different period and the expected differential between the city and the countryside are taken into account. It is, in any case, hard to say whether these values depict the real

\footnotetext{
${ }^{44}$ According to the Church, the salvation of the child's soul was more important than the mother's health. Corsini and Sandri, 'La nascita della pediatria', 10.
} 
Table 2. Births (B), maternal deaths (MD) and maternal mortality rate $(\times 1,000$ births $)$ in the studied populations

\begin{tabular}{|c|c|c|c|c|c|c|c|c|c|c|c|c|}
\hline \multirow[t]{2}{*}{ Period } & \multicolumn{3}{|c|}{ Parma province } & \multicolumn{3}{|c|}{ Casalguidi } & \multicolumn{3}{|c|}{ Civitella del Tronto } & \multicolumn{3}{|c|}{ Alghero } \\
\hline & B & $M D$ & Rate & B & MD & Rate & B & MD & Rate & B & $\mathrm{MD}$ & Rate \\
\hline$<1800$ & 2,785 & 14 & 5.03 & & & & & & & & & \\
\hline 1800-1899 & 11,141 & 93 & 8.35 & 3,565 & 24 & 6.73 & 8,122 & 34 & 4.19 & 10,883 & 74 & 6.80 \\
\hline 1900-1935 & & & & & & & 6,741 & 25 & 3.71 & 12,285 & 52 & 4.23 \\
\hline Total & 13,926 & 107 & 7.68 & 3565 & 24 & 6.73 & 14,863 & 59 & 3.97 & 23,168 & 126 & 5.44 \\
\hline
\end{tabular}

level of maternal mortality in pretransitional Italy or whether they are only the consequence of some inconsistencies in the recording of births and/or deaths. There are qualitative and quantitative elements supporting both hypotheses. For example, in a book published in 1832 in Parma, Lorenzo Molossi reported that in the maternity hospital of Parma, only 3 maternal deaths of 1,011 childbirths were recorded in the years 1821-30. This would seem to support the hypothesis of low maternal mortality levels in the town of Parma at the beginning of the 19th century. ${ }^{45}$ On the other hand, no maternal deaths were found during the Napoleonic campaigns of the beginning of the 19th century (1800-15) either in the Parma province or in Civitella. This might suggest that the registration of deaths and/or births suffered in this turbulent period of Italian history. Generally speaking, when maternal mortality is estimated indirectly from the number of live births, as it is in this study, some issues may negatively affect the estimate. First of all, there is the issue of stillborn babies. These were, in fact, usually excluded from the parish birth registers: this was true even in the case of an emergency baptism, that is, a baptism administered by the midwife to a newborn in danger of death. However, diagnostic problems in differentiating between stillborn deaths and early neonatal deaths make it difficult to have reliable estimates even when based on civil records. ${ }^{46}$ Such an underregistration of stillborn births is then likely to lead to an underestimate in maternal mortality due to the strong relationship between stillbirths and a mother's death and the impossibility of relating these deaths to childbearing. Secondly, a large proportion of mothers dying from maternal causes actually died before they were able to give birth. The combination of the two effects could, therefore, affect the maternal mortality estimate more heavily. After the study of detailed data on mothers' deaths from Sweden, Roger Schofield proposed introducing a correction. ${ }^{47}$ According to him, 'the total rate could be predicted fairly accurately from the live-born maternal rate by increasing the latter by 7 per cent and adding a further constant of 2.73 per thousand ${ }^{\prime}{ }^{48}$ Once applied to the figures shown in Table 3, this correction gives us adjusted estimates of maternal mortality in the populations studied, which places them, according to the values outlined in the first section, on the same level as France.

\footnotetext{
${ }^{45}$ L. Molossi, Vocabolario topografico dei ducati di Parma, Piacenza e Guastalla (Parma: Tipografia Ducale, 1832-34).
}

\footnotetext{
${ }^{46} \mathrm{~L}$. Del Panta and R. Rettaroli, Introduzione alla Demografia Storica (Bari: Laterza, 1994).

${ }^{47}$ Schofield, 'Did the Mother Really Die?', 245-46.

${ }^{48}$ Wrigley et al., English Population History, 312.
} 
Table 3. Total maternal mortality rate $(T M M R)(\times 1,000$ births) in the four studied populations

\begin{tabular}{ccccc}
\hline & $\begin{array}{c}\text { Casalguidi } \\
(1819-59)\end{array}$ & $\begin{array}{l}\text { Civitella } \\
(1809-1935)\end{array}$ & $\begin{array}{l}\text { Parma province } \\
(1761-1883)\end{array}$ & $\begin{array}{l}\text { Alghero } \\
(1866-1935)\end{array}$ \\
\hline TMMR & 9.93 & 6.98 & 10.95 & 8.55 \\
\hline
\end{tabular}

Figure 2 shows the number of maternal deaths within 60 days of childbirth for all the populations here studied. We have already noted how this measure can be affected by having the date of baptism rather than the birth date. Some mothers, in fact, appear to have died some days before the birth of their child. Despite this inconsistency, a mother's death becomes, as expected, less likely as time passes from childbirth. About 13 per cent of maternal deaths occurred on the day of childbirth and 50 per cent within 10 days of childbirth. About 85 per cent of mothers' deaths occurred in the first month after delivery, and only 25 (7.9 per cent) women died between 42 and 60 days from childbirth.

As noted earlier, the sample consists of married women aged 15-49 years whose life status after childbirth is known. Because of likely under-registration bias prior to 1817 in some of the communities studied, the period investigated in the analysis of the determinants of maternal mortality spans 1818-1935. Illegitimate births of women, who subsequently married have been excluded because they obviously did not predict maternal death.

To analyse individual maternal mortality data, a Gompertz duration model is usually and profitably adopted as its steadily decreasing functional form nicely fits the declining trend of the risk of maternal death after childbirth. The aim of such a regression is to measure the effects of a set of variables on the hazard of maternal death. ${ }^{49}$ We estimated two models, a basic model aimed at capturing the effects of biodemographic factors on maternal mortality (Table 4$)^{50}$ and a second, more complex model, including variables concerning exogenous factors of demographic and of a socio-economic nature. ${ }^{51}$ This second model is specifically aimed at highlighting the possible effects of context variables, which could play a relevant role in the rural and familistic societies of Italy, namely grain prices and household structure. The basic model estimates the effects on maternal mortality of six different variables. Community is a covariate whose aim is twofold. On one hand, it should stress the intrinsic differences among the communities studied, in particular those concerning the epidemiological characteristics of each setting; on the other hand, it should control for differentials over time due to the different time intervals analysed in the various populations. Plenty of studies have highlighted the role

\footnotetext{
${ }^{49}$ The effects of single factors (variables) in a Gompertz regression model are here measured (see Tables 4-6) through hazard ratios (HR), which are exponentiated regression coefficients. Values higher than one mean odds increase, whilst values lower than one mean odds decrease. In particular, when the variable is continuous (i.e. CDR), HR indicates the change in the hazard 'per' one unit increase in the variable, and when the variable is categorical (i.e. Multiple Births), it indicates the change in the hazard with respect to a reference category. For technical details on the use of Gompertz models in the study of maternal mortal-
}

ity, see F. Scalone, 'Effects of Nutritional Stress and Socioeconomic Status on Maternal Mortality in Six German Villages, 1766-1863', Population Studies, 2014, 68, 217-36.

${ }^{50}$ Högberg, 'Maternal Mortality', 14-7; Hammel and Guillikson, 'Maternal Mortality as an Indicator', 29091.

${ }^{51}$ Collinearity problems have been tested through the variance inflation factor (VIF), which returned results supporting the absence of collinearity in both models. 


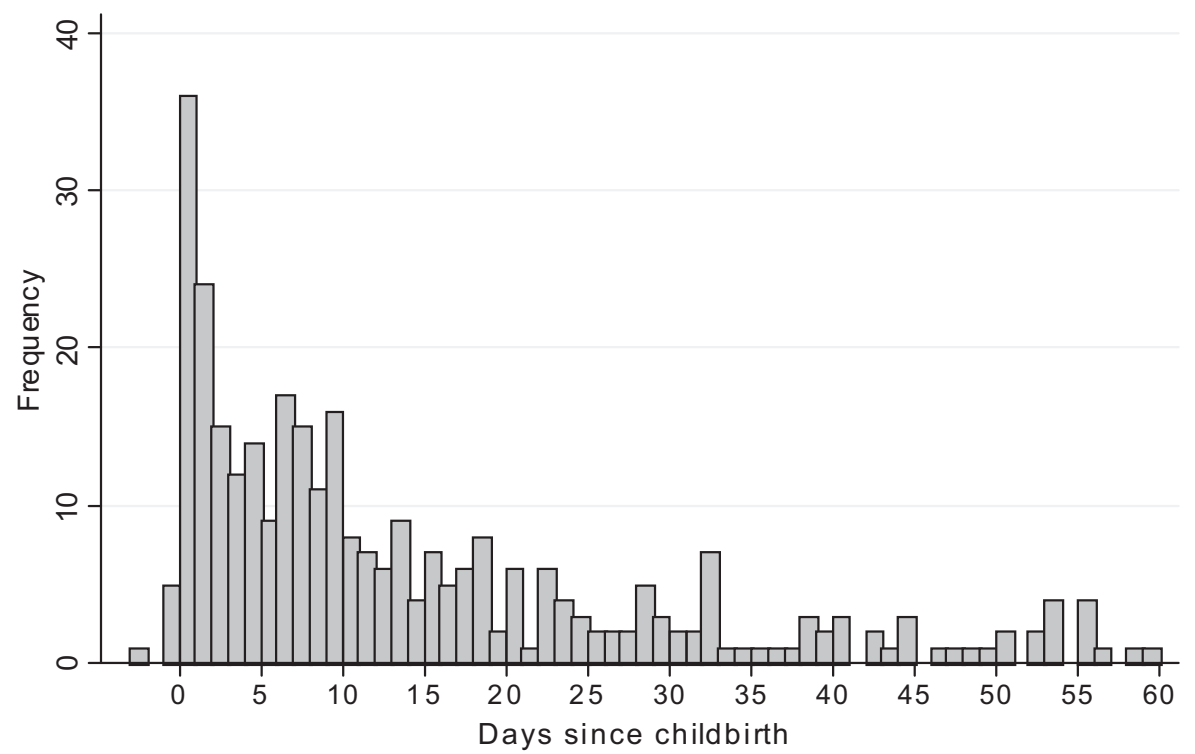

Fig. 2 Number of maternal deaths within 60 days after childbirth for all populations.

of mother's age at birth on maternal mortality, emphasising its U-shaped association. According to those findings, the higher risks of maternal mortality are at the extremes of the age scale regardless of parity. Older women are more likely to develop complications associated with haemorrhage and toxaemia, while the youngest are believed to be more exposed due to inexperience, physiological immaturity and competing nutritional needs between them and their offspring. ${ }^{52}$ However, some recent findings on contemporary data have cast some doubts on the higher mortality of young mothers, hypothesising a J-shaped association. ${ }^{53}$ This is the reason why a categorical variable has been used. A nonlinear effect on mother's death has also been proved for parity. ${ }^{54}$ Primiparous and high-fertility women are, in fact, expected to share the highest risks of death. The primiparous would suffer most from obstructed labour, while high-fertility women would be clearly more exposed to maternal depletion. As for the length of the birth interval, ${ }^{55}$ shorter intervals might be more burdensome for mothers, both for physiological and social reasons. ${ }^{56}$ Close births are more likely associated not only with the premature rupture

${ }^{52}$ D. A. Lawlor, L. Mortensen and A. N. Andersen, 'Mechanisms Underlying the Associations of Maternal Age with Adverse Perinatal Outcomes: A Sibling Study of 264695 Danish Women and Their Firstborn Offspring', International Journal of Epidemiology, 2011, 40, 1205-14.

${ }^{53} \mathrm{M}$. C. Restrepo-Mendez and C. G. Victora, 'Maternal Mortality by Age: Who is Most at Risk?', The Lancet Global Health, 2014, 2, 120-21.

${ }^{54}$ Scalone, 'Effects of Nutritional Stress', 228; B. E. Ory and F. W. A. Van Poppel, 'Trends and Risk Factors of
Maternal Mortality in Late-nineteenth-century Netherlands', The History of the Family, 2013, 18, 481-509.

${ }^{55}$ For firstborn, the interval between marriage and the first birth has been calculated.

${ }^{56}$ Some authors, however, have cast doubts on the strength of the relationship between short birth intervals and maternal mortality as consequence of maternal depletion. See B. Winikoff, 'The Effects of Birth Spacing on Child and Maternal Health', Studies in Family Planning, 1983, 14, 231-45; C. Ronsmans 
Table 4. Gompertz regression, hazard ratios of maternal mortality, 1818-1935

\begin{tabular}{lrrr}
\hline Variables & HR & $p$ & Freq. \\
\hline Population (ref. Civitella) & 1.000 & & 28.5 \\
$\quad$ Province of Parma & 3.090 & $<0.001$ & 19.0 \\
Casalguidi & 1.704 & 0.033 & 6.9 \\
$\quad$ Alghero & 1.472 & 0.017 & 45.6 \\
Mother's age (years) at birth (ref. 21-39) & 1.000 & & 84.4 \\
$\quad<21$ & 1.001 & 0.996 & 4.9 \\
40-49 & 1.716 & 0.002 & 8.4 \\
Unknown & 0.358 & 0.045 & 2.3 \\
Parity (ref. 2-3) & 1.000 & & 32.2 \\
1 & 1.241 & 0.280 & 20.4 \\
4+ & 1.318 & 0.069 & 38.4 \\
Unknown & 1.230 & 0.366 & 9.0 \\
Birth interval (years) (ref. 1.5-3) & 1.000 & & 62.6 \\
$\quad<1.5$ & 1.332 & 0.076 & 22.4 \\
4+ & 1.843 & 0.001 & 7.4 \\
Unknown & 1.252 & 0.359 & 7.7 \\
Multiple births (ref. no) & 1.000 & & 98.8 \\
$\quad$ Yes & 2.891 & $<0.001$ & 1.2 \\
Child dead within 5 days from birth (ref. no) & 1.000 & & 97.0 \\
$\quad$ Yes & 7.066 & $<0.001$ & 3.0 \\
Gamma & -0.061 & $<0.001$ & \\
Observations (births) & 50,744 & & \\
Maternal deaths & 301 & & \\
Log-likelihood & $-2,212.4$ & & \\
\hline
\end{tabular}

of membranes, puerperal endometritis and anaemia but also with problems arising from the many duties and responsibilities associated with the care of a number of little children typical of pretransitional societies. ${ }^{57}$ However, higher risks of maternal death have also been associated with longer birth intervals, especially in relation to the development of pre-eclampsia. ${ }^{58}$ Alternative explanations include the possibility that long birth intervals might actually hide miscarriages, indicative of a selected sub-population of women with higher risks of health problems at childbirth and the role of poor nutrition on female subfecundity in poor societies. ${ }^{59}$ Multiple births and stillbirths have always been claimed as key factors in maternal mortality. A series of biological complications during and after childbirth have been documented to affect the survival of mothers experiencing both

and O. Campbell, 'Short Birth Intervals Don't Kill Women: Evidence from Matlab, Bangladesh', Studies in Family Planning, 1998, 29, 280-90.

${ }^{57}$ A. E. Imhof, 'The Amazing Simultaneousness'; K. Lynch and J. Greenhouse, 'Risk Factors for Infant Mortality in Nineteenth-Century Sweden,' Population Studies, 1994, 48, 117-33; M. Breschi and R. Derosas, 'The Contribution of the EurAsian Project to the Demographic History of Italy: Results and Perspectives on Infant and Child Mortality', in M. Neven and C. Capron, eds, Family Structures,
Demography and Population. A Comparison of Societies in Asia and Europe (Liège: Laboratory of Demography, 2000), 211-34.

${ }^{58}$ Conde-Agudelo and Belizan, 'Maternal Morbidity', 1256-58; G. Dekker and P. Y. Robillard, 'The Birth Interval Hypothesis-Does it Really Indicate the End of the Primipaternity Hypothesis', Journal of Reproductive Immunology, 2003, 59, 245-51.

${ }^{59} \mathrm{R}$. Lesthaeghe and H. J. Page (eds), Child-Spacing in Tropical Africa-Traditions and Change (London: Academic Press, 1981). 
multiple births and stillbirths. ${ }^{60}$ In our analysis, we have used two binary variables to account for the effects of these factors. However, because of the problematic definition of stillbirth not only in parish registers but, to some extent, also in civil records, the death of the child within 5 days of birth was considered as such. ${ }^{61}$

The results not only show some expected outcomes but also some peculiarities. As for populations, Civitella presents the lowest hazard ratio of maternal mortality, whilst the Parma province has the highest. The outcome reflects especially the different periods studied, earlier for Parma and Casalguidi, more recent for Civitella and Alghero. As many studies have shown, adult mortality began to decline in Italy only in the last two decades of the 19th century. ${ }^{62}$ But the first two decades of the 20th century were still very difficult years because of the First World War and the pandemic flu. Then, it was only after 1918 that overall mortality and maternal mortality declined more markedly. This finding provides (partial) confirmation of what emerged from the official statistics of maternal mortality shown in Figure 2.

As for mother's age at birth, the effects on the hazard of maternal death are modest and no U-shaped effect has been found. The coefficient associated with the youngest mothers resulted, in fact, to not be statistically significant. The only association is, therefore, limited to the old age component. Older mothers were positively and significantly associated with maternal mortality, being 75 per cent more likely to die after childbirth when compared with mothers aged 23-39 years. High-parity women (more than four children) were significantly 31 per cent more likely to die than mothers of two to three parity, whilst primiparous mothers showed no significant effect. As for birth interval, we found a J-shaped association between interval length and the hazard ratio of mother's death. Short ( $<1.5$ years) and especially long birth ( $4+$ years) intervals showed higher hazard ratios of maternal mortality when compared with birth intervals between 1.5 and 4 years ( +35 per cent and +86 per cent, respectively). However, if primiparous mothers are excluded from the sample, thereby limiting the analysis to strict interbirth intervals, the hazard ratio curve becomes much more $U$-shaped (+45 per cent and +66 per cent, respectively), with both shorter and longer intervals being statistically significant at $p<0.05$. In the light of the theory of maternal depletion syndrome, older age, high parity and close birth intervals should represent risk factors for that specific syndrome. As for the effect of longer birth intervals on maternal mortality, this could be a sign, as anticipated, either of the presence of non-recorded miscarriages or of subfecundity due to

${ }^{60}$ A. Conde-Agudelo, J. Belizan and G. Lindmark, 'Maternal Morbidity and Mortality Associated with Multiple Gestations', Obstetrics \& Gynecology, 2000, 95, 899-904; A. Picaud et al., 'Risque perinatal et maternel de grossesses multiple', Revue Francaise de Gynecologie et d'Obstretique, 1989, 84, 381-91; I. Loudon, Death in Childbirth. An International Study of Maternal Care and Maternal Mortality 1800-1950 (Oxford: Oxford University Press, 1992).

${ }^{61}$ Actually, the death of a child within 5 days from birth can either be a cause of a mother's death or a consequence of this event, denoting the existence of a reverse causation effect between those two factors. The problem is, however, not easily resolved be- cause, as already mentioned, religious sources do not allow for any differentiation between 'real' stillbirths and children who died just a few days after birth. One should, therefore, be very wary in the interpretation of the direction of causality. M. Breschi et al., 'The Sardinian Experience of the Lowest Italian Infant Mortality at the Turn of the Twentieth Century. True or False Empirical Evidence?', Annales de Demographie Historique, 2012, 1, 63-94.

${ }^{62}$ S. Caselli, 'Mortalità degli adulti e differenze di genere nella prima fase della transizione demografica', in M. Breschi and L. Pozzi, eds, Salute, malattia e soprawivenza in Italia fra '800 e '900 (Udine: Forum, 2007), 293-310. 
poor nutrition. Finally, as expected, multiple births and the death of the baby within 5 days of birth were the most important determinants of maternal mortality. Mothers with multiple births were three times more likely to die than uniparous mothers were, while the death of the child in the very first days after delivery was associated with a six times increase in the hazard ratio of mother's death.

In the second model (Table 5), the effect of grain price (logged) is analysed along with the level of background mortality, measured by means of the crude death rate (CDR): namely the ratio between total deaths and population size in a given year. It is common in historical demography to use grain prices as a proxy for food consumption. Increases in prices could worsen food availability, and consequently nutritional status and health of newly mothers, concurring to exacerbate maternal depletion. ${ }^{63}$ However, maternal mortality is also associated with community background mortality, ${ }^{64}$ whose levels did not obviously depend only on price fluctuations. The introduction of CDR aims exactly at controlling all that part of background mortality not directly associated with grain price fluctuations. As for our populations, we collected wheat price series from the market of Parma (used for the province of Parma), the market of Florence (used for Casalguidi) and the market of Sassari (for Alghero). ${ }^{65}$ No price data were available for Civitella. CDR and grain price trends for the period 1818-1922 are shown in Figure 3 for the populations for which they are available.

There is a close association between CDR and grain prices fluctuations and important socio-economic, demographic and temporal differences among populations. Given this, the analysis of the effects of grain price and CDR on maternal mortality has been investigated by means of an interaction, once controlled for all the other covariates described in Table 4. In particular, two interaction terms were added, each of them concerning one of the context variables (grain price and CDR) and a dummy variable for populations, contrasting Alghero with the other communities studied. ${ }^{66}$ The analysis has been limited to populations and to years for which both CDR and grain prices were available, namely 1818-1922.

None of the context variables, neither CDR nor prices, returned a significant effect on maternal mortality in any of the communities studied. One possible partial explanation is that food availability may have been unaffected by price fluctuations on account of the

\footnotetext{
${ }^{63}$ Scalone, 'Effects of Nutritional Stress'.

${ }^{64}$ Actually, background adult mortality was better suited than overall mortality to represent maternal mortality. However, the assessment of the local levels of adult mortality based on family reconstitution methods is difficult and often subject to stochastic fluctuations when estimated for small populations. Annual population sizes were then determined from the Status Animarum for Casalguidi and Madregolo, from post-unitary annual demographic statistics for the municipalities of Alghero and Civitella del Tronto, while for the pre-unity years for Civitella, they have been estimated by means of Inverse Projection techniques based on civil statistics and some Bourbon censuses.

${ }^{65}$ Time series of prices come from different sources. For Parma, see P. L. Spaggiari, L'agricoltura negli stati
}

Parmensi dal 1750 al 1859 (Milan: Banca Commerciale Italiana, 1966) and 'I prezzi di generi alimentari sul mercato di Parma', Archivio economico dell'unificazione italiana, I-VIII, 3. For Florence, see P. Bandettini, 'I prezzi sul mercato di Firenze dal 1800 al 1890', Archivio economico dell'unificazione italiana, 5th series, 1 (Turin: ILTE, 1957). For Sassari, the price series was reconstructed using raw data from the Market Price Registers kept within the local historical Archive.

${ }^{66}$ Prices have been included in the model after detrending of time series by means of the HodrickPrescott filter, which is widely used in macroeconomic studies to extract cyclical movements about trends in time series. 

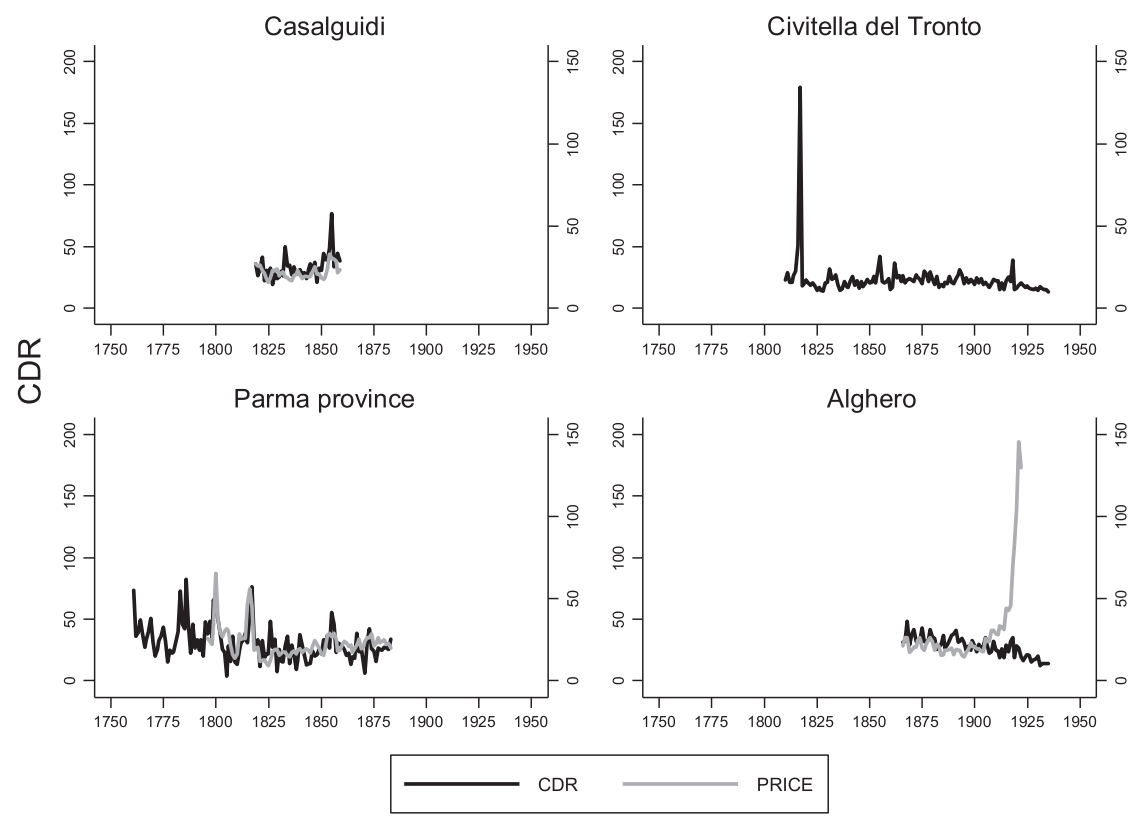

Fig. 3 CDR and price trends in the populations studied, 1818-1923.

rural nature of the communities studied (Alghero included). This might have guaranteed families and individuals with enough food through the year even in difficult times.

The last analysis we carried out is for household structure. In the theory of maternal depletion, the necessity to resume farm work, house work and child care just after childbirth could worsen the health conditions of mothers leading to physical and mental exhaustion. ${ }^{67}$ In societies lacking social institutions aimed at the assistance and care of mothers, individuals could often count only on the help of kin. ${ }^{68}$ This is especially true for Italy at the turn of the 20th century, where the dependence on home births made the household the primary setting for maternal health care. Usually, the technique of family reconstitution based on religious or civil records does not allow for such effects because it does not provide any clue for the co-residential pattern. This latter information is, however, fundamental for understanding the possible redistribution within the family group

\footnotetext{
${ }^{67}$ Oris, Neven and Alter, 'Maternal Depletion', 162-68; E. A. Hammel and A. Gullickson, 'Kinship Structure and Survival: Maternal Mortality on the Croatian Border 1750-1898', Population Studies, 2004, 58, 145-59; A. Reid, 'Infant Feeding and Post-Neonatal Mortality in Derbyshire, England, in the Early Twentieth Century', Population Studies, 56, 151-66.

${ }^{68}$ Previous studies have already proven the positive effects of complex households on the survival of their weakest members. See D. I. Kertzer, 'Toward a Historical Demography of Aging', in D. I. Kertzer and
}

P. Laslett, eds, Aging in the Past: Demography, Society and Old Age (Berkeley: University of California Press, 1995), 363-83; R. Derosas and O. Saito, 'Introduction', in R. Derosas and M. Oris, eds, When Dad Died. Individuals and Families Coping with Distress in Past Societies (Bern: Peter Lang, 2002), 113; M. Breschi, R. Derosas and M. Manfredini, 'Infant Mortality in Historical Italy: Interactions Between Ecology and Society', in T. Bengtsson and O. Saito, eds, From Hunger to Modern Economic Growth (Oxford: Oxford University Press, 2000), 457-90. 
of mother's work and duties after childbirth. In this study, the availability of continuous census data for Casalguidi and Madregolo has allowed a precise and detailed assessment of the household structure year after year. A categorical variable indicating the structure of the household (nuclear, extended, multiple, undefined) in which the mother lived at the moment of delivery has, therefore, been added to the basic model. Although based on a limited sample (about 5,300 births and 35 maternal deaths), the results show (Table 6) that living in a nuclear household increases the hazard of maternal mortality by about 52 per cent, when compared with living in a complex household (statistically significant at the 10 per cent level). The hazard for those living in extended households is conversely not statistically significant, although the coefficient is in line with that of multiple households. The results prove that, in sharecropping societies, large and complex households may provide mothers with more effective assistance than simpler family groups could do, thereby lowering their risk of maternal death. Usually, many female members of complex households (daughters, sisters or other female kin) might, in fact, help newly mothers by taking over their family duties. In this way, they give them time to recover from the stress of childbirth. ${ }^{69}$ This was clearly less likely in nuclear family contexts, where the mother was often the only female adult in the household and was forced to take care of children and run the household almost immediately after childbirth.

As nuclear households were usually poorer than multiple ones, a further model concerning only Casalguidi was run to disentangle household well-being effects from those associated with household structure. The results (not shown here for the sake of brevity) demonstrate that the pattern holds even when the economic situation of the family is controlled for. This implies that the effect of household structure on maternal mortality is strictly associated with the composition of the household rather than household's economic resources.

\section{Discussion and Conclusive Remarks}

This study provides the first organic effort to analyse maternal mortality in pretransitional and early transitional Italy, a topic that Italian historical demographers have never tackled systematically. Based on individual data from different populations across Italy, the analyses have not only provided further confirmation of well-known theories, but they have also raised new queries and interpretations.

Estimates of the levels of maternal mortality, once corrected for missing stillbirths, put our Italian communities on the same level as other European countries, even those in a more advanced stage of demographic transition such as France.

As for the determinants of maternal mortality, the results provide contrasting findings. On one hand, the significant and positive effects of old age, close birth intervals and high parity on maternal mortality appear to be indirect evidence of the role of maternal depletion. On the other hand, the statistically insignificant role of grain prices would seem to

\footnotetext{
${ }^{69}$ For a description of the roles and relationships among the members of sharecropping households, see A. Doveri, 'Land, Fertility, and Family: A Selected Review of the Literature in Historical Demography', Genus, 2000, LVI, 19-59; G. Biagioli, 'La diffusione della mezzadria nell'Italia centrale: Un modello di svi-
}

luppo demografico ed economico', Bollettino di Demografia Storica, 1986, 3, 59-66; M. Manfredini and M. Breschi, 'Living Arrangements and the Elderly: An Analysis of Old-Age Mortality by Household Structure in Casalguidi, 1819-1859', Demography, 2013, 50, 1593-613. 
Table 5. Gompertz regression, hazard ratios of maternal mortality: effects of grain price and CDR, 18181922

\begin{tabular}{lll}
\hline & HR & $p$ \\
\hline Community (ref. Casalguidi and Parma) & 1.000 & \\
Alghero & 0.254 & 0.013 \\
CDR & 0.995 & 0.523 \\
CDR * Alghero & 1.028 & 0.112 \\
Price & 1.057 & 0.214 \\
Price * Alghero & 0.951 & 0.311 \\
\hline
\end{tabular}

Table 6. Gompertz regression, hazard ratios of maternal mortality: effects of household structure in Madregolo and Casalguidi, 1818-1859

\begin{tabular}{llcr}
\hline & HR & $p$ & Freq. \\
\hline Household structure (ref. multiple) & 1.000 & & 29.9 \\
Extended & 1.059 & 0.938 & 19.6 \\
Nuclear & 1.519 & 0.097 & 37.6 \\
Unknown/undefined & 0.735 & 0.726 & 12.9 \\
\hline
\end{tabular}

suggest that economic stresses had little effect on food availability in rural communities and, consequently, on the survival of women who had just given birth. If malnutrition is key for the maternal depletion syndrome, then our results do not suggest that this disease was particularly widespread. More realistically, what these results seem to suggest is that, although not clinically verifiable, some sort of maternal depletion was definitely common among new mothers living in the rural communities studied here. Italians mothers were burdened by many and frequent childbirths, often giving birth at home without skilled assistance and frequently required to get back to their work duties soon after delivery to supplement a meagre family income. As such, these women obviously suffered not only from risk factors directly associated with delivery but also, and especially, from the consequences associated with the physical exhaustion deriving from the combination of these factors. More than simple food availability, therefore, what mattered most was the extreme difficulty in recovering from the physical consequences of childbearing and delivery.

The evidence of the protective role played by complex household structures on mothers' survival further supports this line of reasoning. Das Gupta found evidence that in the patrilineal joint family system of Northern India, the strong gender division and the lower social role of women yield a higher risk of maternal death because a mother 'may hesitate to mention [any health problem occurring after childbirth] and even when she mentions it the matter will be considered by those senior to her before action is taken' ${ }^{70}$

\footnotetext{
${ }^{70} \mathrm{M}$. Das Gupta, 'Lifeboat Versus Corporate Ethic: Social and Demographic Implications of Stem and 
However, in pretransitional Italian sharecropping societies, family support appears to increase the chances of survival of mothers. Despite the lack of hospitalisation, unskilled assistance during delivery and repeated childbirths, the multiple household guaranteed mothers help. They could be replaced in many everyday activities both during and after childbirth, thereby releasing them from some domestic duties and hard work in the fields. This would reduce physical exhaustion and allow mothers to recover more quickly from childbirth. This appears to have represented a decisive step forward in decreasing the hazard ratio of maternal mortality. In such cases, we can see the family network acting as and effectively replacing an absent welfare state.

Although based on two small sharecropping populations, this finding is sufficient, in our opinion, to encourage further studies looking at the importance of household structure for maternal mortality. There is a strong suspicion that only the complete reconstruction of the co-residential pattern of mothers can help us evaluate possible complex mechanisms of mutual help and care among household members, especially among female subjects. 